\title{
Aging Behaviour in Copper Bearing High Strength Low Alloy Steels
}

\author{
A. N. BHAGAT, S. K. PABI, ${ }^{1)}$ S. RANGANATHAN ${ }^{21}$ and O. N. MOHANTY
}

Tata Steel, Jamshedpur, Jharkhand, Pin-831001 India. $\quad$ 1) Department of Metallurgical and Materials Engineering, IIT Kharagpur, W.B., Pin-721302 India. $\quad$ 2) National Metallurgical Laboratory, Jamshedpur, Jharkhand, Pin-831007 India. E-mail: anbhagat@tatasteel.com,onmohanty@lot.tatasteel.com

(Received on April 18, 2003; accepted in final form on August 20, 2003)

\begin{abstract}
Strengthening due to precipitation of copper and microalloying elements is a phenomenon utilized in the design of some HSLA steels for naval structural applications. In the present work, precipitation of copper and associated property changes during aging of three Cu-containing HSLA steels were investigated. Electrical resistivity change during isothermal aging of one low carbon steel was compared with that for HSLA steels with a view to evaluating the kinetics of copper precipitation in the latter. The results fitted to Johnson-Mehl-Avrami equation indicate that this precipitation occurs in two consecutive stages with activation energy in the range of $114-128 \mathrm{~kJ} / \mathrm{mol}$ and $64-77 \mathrm{~kJ} / \mathrm{mol}$, respectively. These values suggest a dominant role of the high dislocation density of the martensite matrix in the aging process. The peak hardness during isochronal $(1 \mathrm{~h})$ aging was observed in the aging temperature range of $500-550^{\circ} \mathrm{C}$, whereas Charpy impact toughness was lowest for the samples aged at $450^{\circ} \mathrm{C}$. The fractographs of the Charpy specimens were in good agreement with the impact strength measurements, apparently indicating an adverse effect of coherent copper precipitates on the impact properties.
\end{abstract}

KEY WORDS: HSLA steel; tempering; copper precipitation; electrical resistivity; aging.

\section{Introduction}

Copper containing High Strength Low Alloy (HSLA) steels, typically HSLA-80 and HSLA-100, are of particular interest for large submarine and offshore structures, linepipes, hull of ships, etc. These applications often demand a combination of strength, toughness and weldability. ${ }^{1)}$ In order to attain the desired properties, several alloying elements, such as $\mathrm{Mn}, \mathrm{Cu}, \mathrm{Ni}, \mathrm{Cr}, \mathrm{Mo}, \mathrm{Nb}$ etc., are added to exploit the benefits from the alloy chemistry. However, for obtaining very high strength level (i.e. $550 \mathrm{MPa}$ in HSLA80 and $690 \mathrm{MPa}$ in HSLA-100) copper addition plays a crucial role, as it contributes to strength through the precipitation hardening process. ${ }^{2,3)}$ The amount of copper precipitating as well as its size and morphology govern the properties of the copper bearing steel.

Although the precipitation of copper in iron base systems has been studied by several investigators ${ }^{4-9)}$ only a few reports $^{10-12)}$ are available on the precipitation of copper in HSLA steels i.e. in a multi alloying environment. Various techniques such as hardness measurements, TEM, FIM, SANS $^{6-9)}$ and so on have been used for these studies but these tools are inadequate to study continuously the phenomenon of copper precipitation and estimate the amount of copper precipitates at various temperatures. Measurement of electrical resistivity continuously as a function of temperature and time is an effective means of studying the kinetics of precipitation in steel. This tool has been used for a few elements in steels ${ }^{13-16)}$ but none has used to study the precipitation of copper in HSLA steels where complex alloying environment prevails.

The present study attempts to gain a deeper insight into the precipitation process of copper and associated change during aging.

\section{Experimental}

Three varieties of HSLA steels (S1, S2 and S3) supplied by the Naval Research Laboratory, USA, in plate form (32-50 $\mathrm{mm}$ thick) were used for the present study. The plates were $50 \mathrm{~mm}$ thick for S1 and S3, and $32 \mathrm{~mm}$ for S2 steel. One low carbon steel (LCS) produced by Tata Steel company as transfer bar ( $25 \mathrm{~mm}$ thick) was also used in this investigation. The chemical compositions of the steels were analyzed by optical emission spectroscopy method and are reported in Table 1. The composition of the S1 and S2 steel falls in the category of the HSLA-100 steel, whereas the steel S3 is a typical HSLA-80 steel.

For resistivity studies, the samples were machined down to $8 \mathrm{~mm}$ diameter rods, then drawn to $0.5 \mathrm{~mm}$ diameter wires through successive passes with intermediate annealing at $900^{\circ} \mathrm{C}$. The wires were annealed at $900^{\circ} \mathrm{C}$ in vacuum $\left(1.33 \times 10^{-4} \mathrm{~Pa}\right)$ for $1 \mathrm{~h}$ and slowly cooled in the furnace. The annealed wires of approximately $100 \mathrm{~mm}$ length were placed in the quartz capsules, which were repeatedly flushed with argon and evacuated. The sealed capsules were 
Table 1. Chemical compositions of HSLA and plain C steels (in wt \%).

\begin{tabular}{|l|c|c|c|c|c|c|c|c|c|c|c|c|c|}
\hline Steel & $\mathrm{C}$ & $\mathrm{Mo}$ & $\mathrm{Cr}$ & $\mathrm{Mn}$ & $\mathrm{Cu}$ & $\mathrm{Ni}$ & $\mathrm{Nb}$ & $\mathrm{Al}$ & $\mathrm{Ti}$ & $\mathrm{N}$ & $\mathrm{S}$ & $\mathrm{Si}$ & $\mathrm{P}$ \\
\hline $\mathrm{S} 1$ & 0.038 & 0.57 & 0.54 & 0.87 & 1.98 & 3.39 & 0.032 & 0.038 & 0.003 & 0.0145 & 0.003 & 0.23 & 0.002 \\
\hline S2 & 0.04 & 0.60 & 0.57 & 0.86 & 1.58 & 3.55 & 0.03 & 0.032 & 0.003 & 0.0145 & 0.004 & 0.27 & 0.002 \\
\hline S3 & 0.044 & 0.60 & 0.58 & 0.95 & 1.23 & 1.65 & 0.037 & 0.023 & 0.003 & 0.0142 & 0.006 & 0.34 & 0.005 \\
\hline LCS & 0.03 & - & - & 0.13 & - & - & - & 0.03 & - & 0.005 & - & 0.01 & 0.015 \\
\hline
\end{tabular}

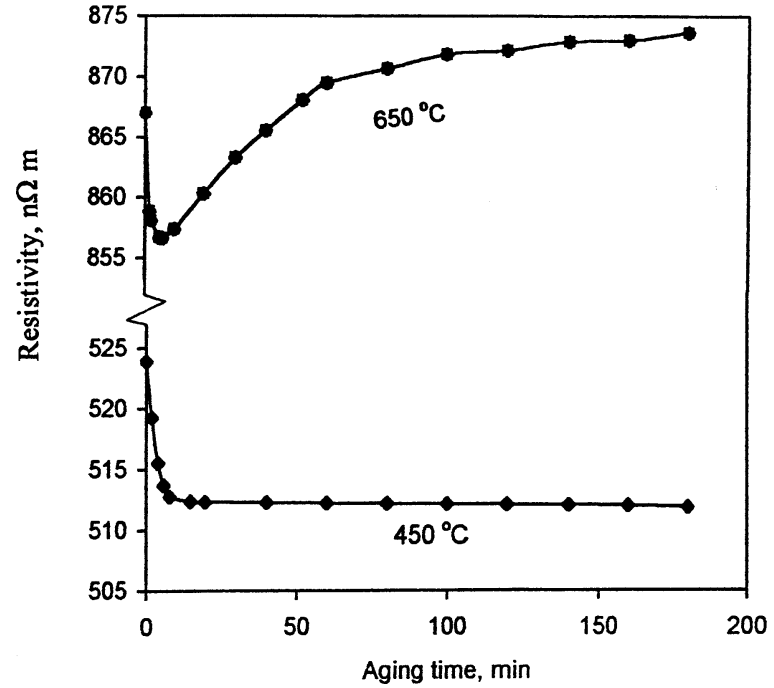

Fig. 1. Variation in electrical resistivity of low carbon steel measured as a function of aging time at $T_{\mathrm{A}}=450$ and $650^{\circ} \mathrm{C}$.

heated to $900^{\circ} \mathrm{C}$, held at that temperature for $1 \mathrm{~h}$ and quenched in water. Wire samples of approximately $20 \mathrm{~mm}$ length were taken as the specimen and welded to the sample holder of the resistivity apparatus (Sinko-Riko, model TER-2000 RH). The quenched wires of the HSLA steels were heated to different aging temperatures $\left(T_{\mathrm{A}}\right)$ ranging from 450 to $700^{\circ} \mathrm{C}$ in the resistivity apparatus at a heating rate of $0.33^{\circ} \mathrm{C} / \mathrm{s}$ under vacuum. The specimen was held at each aging temperature for a period of $3 \mathrm{~h}$. The resistivity $(\rho)$ was continuously recorded during heating, as well as, during subsequent isothermal holding. Resistivity of the quenched LCS was also continuously recorded at two aging temperatures i.e., 450 and $650^{\circ} \mathrm{C}$.

Samples for hardness measurements, and standard Charpy impact tests were cut from plates of all three HSLA steels. These samples were austenitised at $900^{\circ} \mathrm{C}$ for $1 \mathrm{~h}$ and quenched in water. The quenched samples were then aged at various temperatures $\left(450\right.$ to $\left.700^{\circ} \mathrm{C}\right)$ for $1 \mathrm{~h}$ and cooled in air. Steel S1 was aged for various time periods at different temperature. Hardness was measured by a Vickers's hardness tester using $30 \mathrm{~kg}$ load. Charpy impact tests were carried out using standard V-notch transverse specimens. Fractured surfaces of some selected specimens were examined for fractography by a JEOL (model JXA6400) Scanning Electron Microscope.

\section{Results}

The resistivity change of the quenched low carbon steel during isothermal aging at $T_{\mathrm{A}}=450$ and $650^{\circ} \mathrm{C}$ is displayed

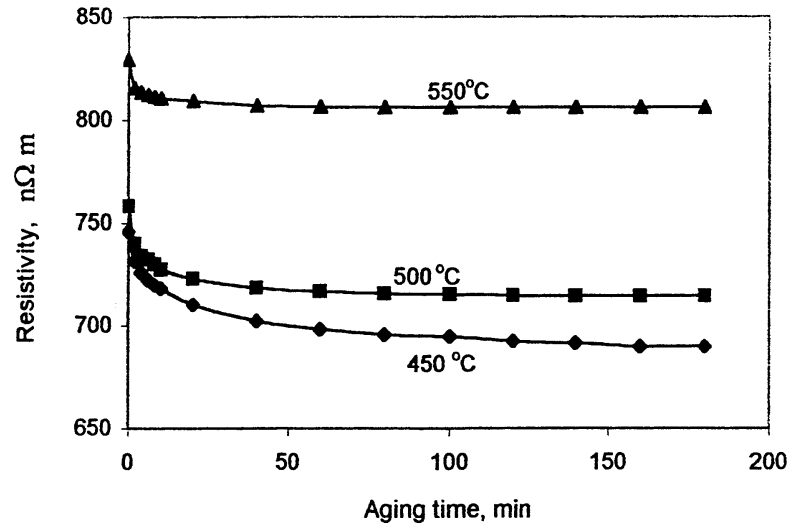

Fig. 2. Time modulation of electrical resistivity of $\mathrm{S} 1$ steel at $T_{\mathrm{A}}=450,500$ and $550^{\circ} \mathrm{C}$.

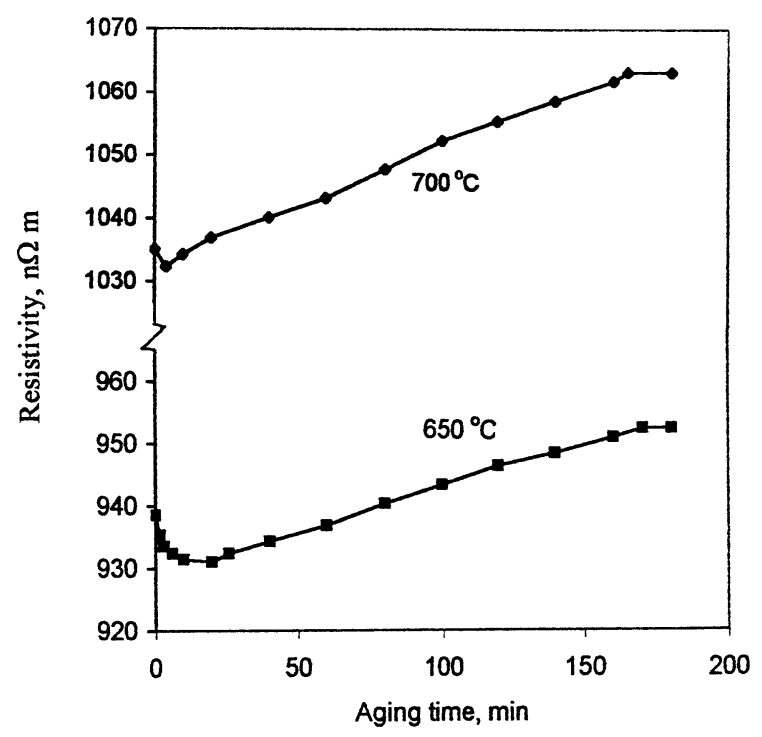

Fig. 3. Electrical resistivity as a function of time for $\mathrm{S} 1$ steel at $T_{\mathrm{A}}=650$ and $700^{\circ} \mathrm{C}$.

in Fig. 1. During aging at $450^{\circ} \mathrm{C}$, the resistivity decreases rapidly and then it becomes almost constant. At $T_{\mathrm{A}}=650^{\circ} \mathrm{C}$, however, the resistivity manifests a gradual increase after a sharp fall in the initial period. After about $2 \mathrm{~h}$ of aging at this temperature, the resistivity value seems to approach a plateau. The $\rho$-time plot for one HSLA steel (S1) at $T_{\mathrm{A}}=450-550^{\circ} \mathrm{C}$ is presented in Fig. 2, whereas at $T_{\mathrm{A}}=650$ and $700^{\circ} \mathrm{C}$ is shown in Fig. 3. The plot in Fig. 2 shows that the resistivity initially declines with time up to a certain period and then it eventually becomes almost constant. At higher temperatures $\left(650\right.$ and $\left.700^{\circ} \mathrm{C}\right)$, initial fall was observed however there was an appreciable rise in the resistivity before it assumed a constant value at very long time. All 


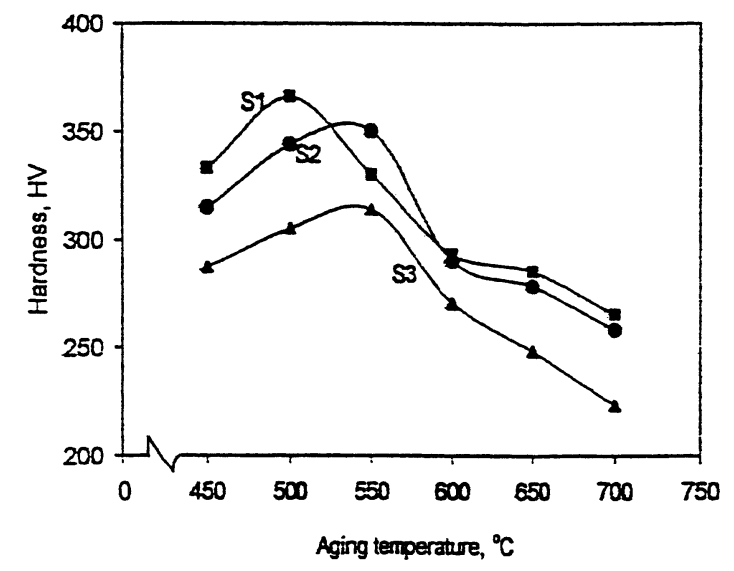

Fig. 4. Effect of aging temperature (aged for $1 \mathrm{~h}$ ) on the hardness of S1, S2 and S3 steels.

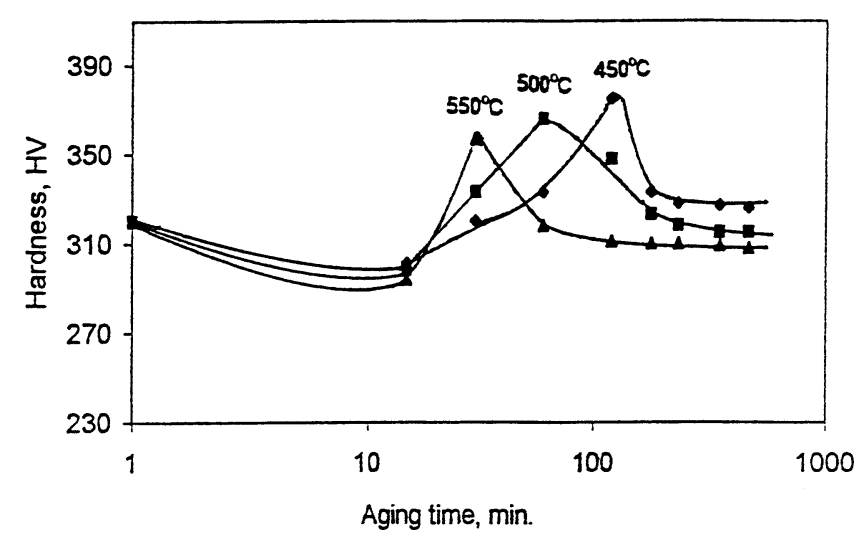

Fig. 5. Variation of hardness with aging time at $T_{\mathrm{A}}=450,500$ and $550^{\circ} \mathrm{C}$ for $\mathrm{S} 1$ steel.

the three steels showed a similar pattern.

The variation of hardness of the S1, S2 and S3 steels as a function of $T_{\mathrm{A}}$ during isochronal aging $(1 \mathrm{~h})$ is shown in Fig 4. All three HSLA steels behaved in a similar manner. The hardness increases with $T_{\mathrm{A}}$, reaches a peak and then continues to fall. The aging temperature corresponding to the peak hardness of S1 steel was $500^{\circ} \mathrm{C}$, whereas for S2 and $\mathrm{S} 3$ steels it was $550^{\circ} \mathrm{C}$. The magnitude of the peak hardness attained in case of S1 steel was higher by about $20 \mathrm{HV}$ and $65 \mathrm{HV}$ than that for S2 and S3 steels, respectively. The hardness as a function of aging time at $T_{\mathrm{A}}=450-550^{\circ} \mathrm{C}$ for $\mathrm{S} 1$ steel is shown in Fig. 5. It is observed that the hardness initially shows a marginal fall following which it rises gradually to a peak before it declines and approaches nearly a constant value at longer times. The magnitude of the peak hardness value for $T_{\mathrm{A}}=450^{\circ} \mathrm{C}$ appears to be the highest and it decreases with the rise in $T_{\mathrm{A}}$. The aging characteristics at higher temperatures are somewhat different. The variation in hardness of $\mathrm{S} 1$ steel with aging time for $T_{\mathrm{A}}=600,650$ and $700^{\circ} \mathrm{C}$ is plotted in Fig 6. It is observed that during aging at 650 and $700^{\circ} \mathrm{C}$, the hardness decreases monotonically with time. In contrast, aging at $600^{\circ} \mathrm{C}$ initially causes a slight increase in hardness, after which, it decreases monotonically (Fig. 6).

Results of the Charpy impact test show that aging for $1 \mathrm{~h}$ at $450^{\circ} \mathrm{C}$ caused a pronounced decrease in the impact value, while at higher $T_{\mathrm{A}}$ up to $650^{\circ} \mathrm{C}$ a steady increase of impact

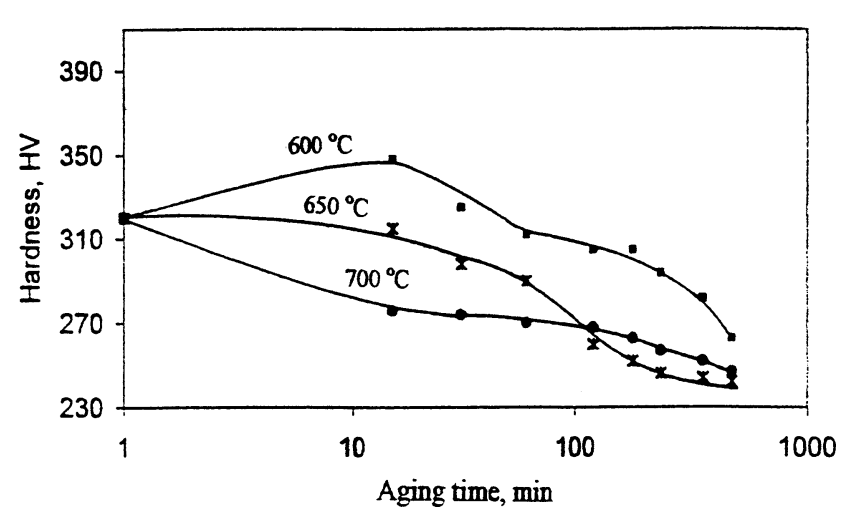

Fig. 6. Variation of hardness with aging time at $T_{\mathrm{A}}=600,650$ and $700^{\circ} \mathrm{C}$ for $\mathrm{S} 1$ steel.

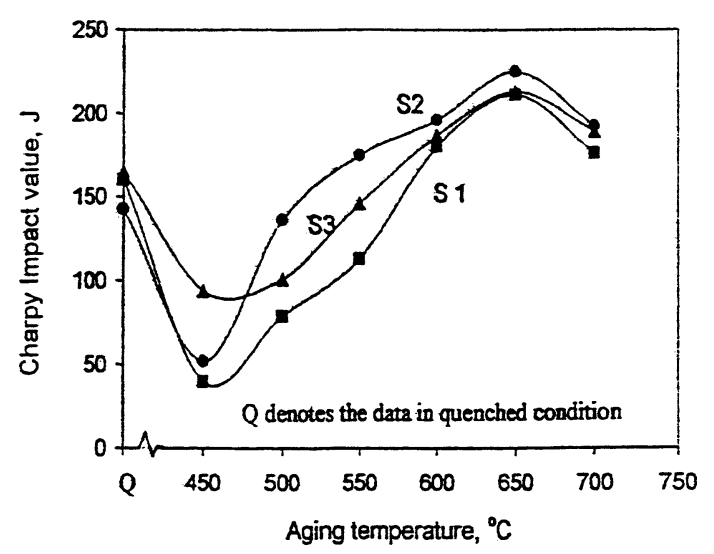

Fig. 7. Effect of aging temperature (aged for $1 \mathrm{~h}$ ) on the Charpy impact properties of S1, S2 and S3 steels.

strength occurred (Fig. 7). However, at still higher $T_{\mathrm{A}}$ a fall in the impact strength was noted. To investigate the fracture behavior of the samples aged at different $T_{\mathrm{A}}$, the fractured surfaces of the Charpy specimens were examined by SEM. The fractographs of S1 and S3 steel samples aged at $450^{\circ} \mathrm{C}$ for $1 \mathrm{~h}$ are shown in Figs. 8(a) and 8(b) respectively. The fracture surface of S1 steel exhibits a predominantly cleavage fracture as against the mix mode of fracture for S3 steel. The fracture behavior of the $\mathrm{S} 1$ and $\mathrm{S} 3$ steel samples aged at $550^{\circ} \mathrm{C}$ for $1 \mathrm{~h}$ is displayed in Figs. 8(c) and 8(d). It reveals a mix mode of fracture for $\mathrm{S} 1$ steel and a predominantly dimple mode of fracture for S3 steel. The SEM fractographs of the $\mathrm{S} 1$ and $\mathrm{S} 3$ steel samples aged at $650^{\circ} \mathrm{C}$ is presented in Figs. 8(e) and 8(f). In this case, a ductile mode of fracture for both the steels is evident from the presence of dimples in the fractured surface.

\section{Discussion}

\subsection{Resistivity}

In HSLA steels, the resistivity gradually decreases with aging time and finally assumes a constant value for $T_{\mathrm{A}}=$ $450-550^{\circ} \mathrm{C}$ (Fig. 2). Low carbon steel follows the same trend at $T_{\mathrm{A}}=450^{\circ} \mathrm{C}$ (Fig. 1). In case of LCS, the decrease in resistivity may be ascribed to the tempering process whereas in HSLA steels, it may be attributed to the combined effects of tempering and copper precipitation. The $t_{0.95}$ (time for $Y=0.95$, where $Y=\left(\rho_{0}-\rho_{t}\right) /\left(\rho_{0}-\rho_{\mathrm{m}}\right) ; \rho_{0}$ is the resistivity at time $t=0, \rho_{t}=$ resistivity at time $t$, and $\rho_{\mathrm{m}}$ is the mini- 


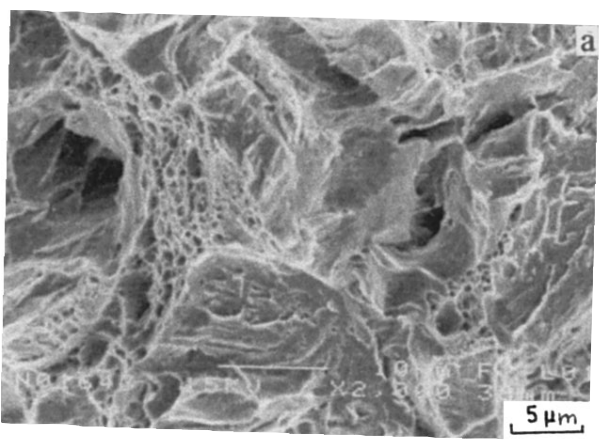

S1 steel aged at $450{ }^{\circ} \mathrm{C}$

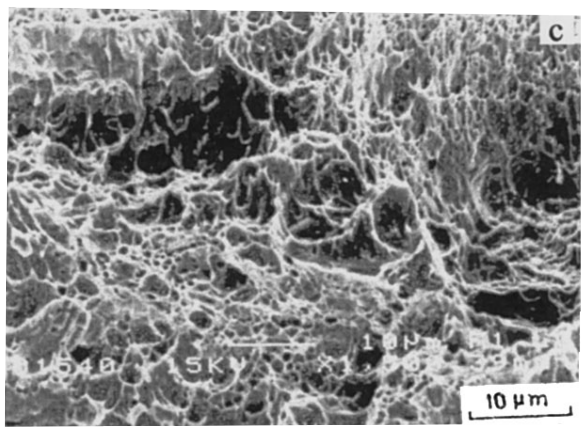

Si steel aged at $550{ }^{\circ} \mathrm{C}$

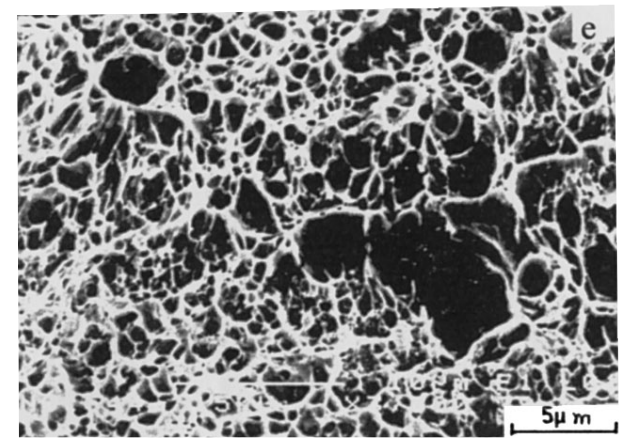

S1 steel aged at $650^{\circ} \mathrm{C}$

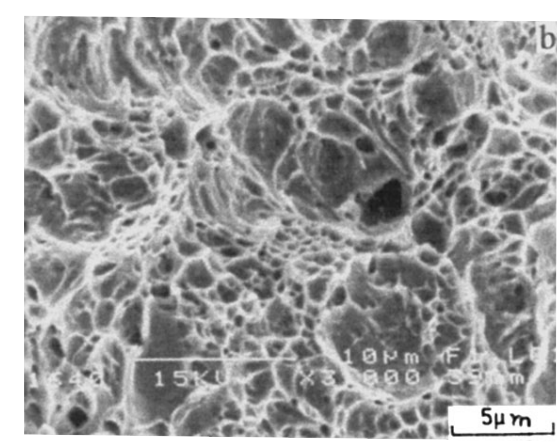

$\mathrm{S} 3$ steel aged at $450^{\circ} \mathrm{C}$

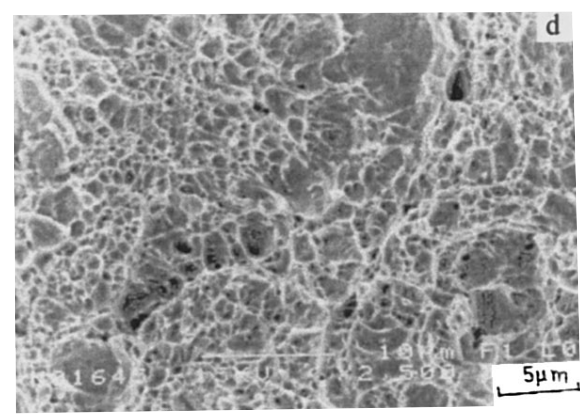

S3 steel aged at $550^{\circ} \mathrm{C}$

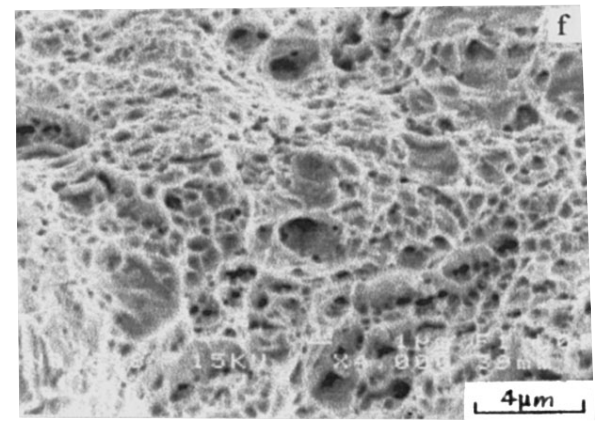

$\mathrm{S} 3$ steel aged at $650^{\circ} \mathrm{C}$

Fig. 8. Photograph of fracture of S1 and S3 steels observed by SEM.

mum value of resistivity) was assumed to be the period when the underlying process (tempering/precipitation) is complete and it was estimated from the resistivity data for HSLA as well as LCS. For S1 steel, $t_{0.95}$ was found to be 140,80 and $40 \mathrm{~min}$ at $T_{\mathrm{A}}=450,500$ and $550^{\circ} \mathrm{C}$, respectively as against 120, 110 and $50 \mathrm{~min}$ for S2 steel and 200, 150 and $80 \mathrm{~min}$ for $\mathrm{S} 3$ steel. In case of LCS, $t_{0.95}$ at $T_{\mathrm{A}}=450^{\circ} \mathrm{C}$ was estimated to be $8 \mathrm{~min}$.

It indicates that the tempering process needs a short period (8 min at $450^{\circ} \mathrm{C}$ in LCS ) as compared to copper precipitation $\left(120-200 \mathrm{~min}\right.$ at $450^{\circ} \mathrm{C}$ in HSLA steels). It is as expected since the copper precipitation would need higher activation energy compared to the conventional tempering process.

\subsubsection{Evaluation of Kinetics of Tempering and Kinetics of Copper Precipitation during Aging}

An attempt was made to evaluate the kinetics of tempering in the low carbon steel and the results were applied to the present HSLA steels to eliminate the contribution of tempering during aging for deriving the kinetics of $\mathrm{Cu}$ pre- cipitation. The fractional decrease in the resistivity in LCS, $Y_{\text {tem }}$, which represents the extent of tempering at a given time was evaluated and a relation between $Y_{\text {tem }}$ and aging time was obtained at various temperatures as shown in Appendix 1.

The Johnson-Mehl-Avrami empirical rate equation, ${ }^{17-19)}$ $Y=1-\exp \left[-(k t)^{n}\right]$, where, $k=$ the empirical rate constant, $t=$ time and $n$ is a constant, was used for analyzing the isothermal resistivity data. After eliminating the effect of tempering, the fractional decrease in the resistivity, $Y=$ $\left(\rho_{0}-\rho_{t}\right) /\left(\rho_{0}-\rho_{\mathrm{m}}\right)$, can be considered proportional to the amount of copper precipitation. The values of $Y$ were plotted as a function of time for $T_{\mathrm{A}}=450,500$ and $550^{\circ} \mathrm{C}$ and displayed in Fig. 9. The function $\log \log [1 /(1-Y)]$ was evaluated as a function of $\log t$ (Fig. 10). At all the temperatures, the plots exhibit two linear segments in case of all three steels. The slope in both the stages at different temperatures evidences the reaction to be isokinetic having activation energies in the range of $114-126$ and $64-77 \mathrm{~kJ} / \mathrm{mol}$, respectively.

The activation energy in the first stage may be associated 
ISIJ International, Vol. 44 (2004), No. 1
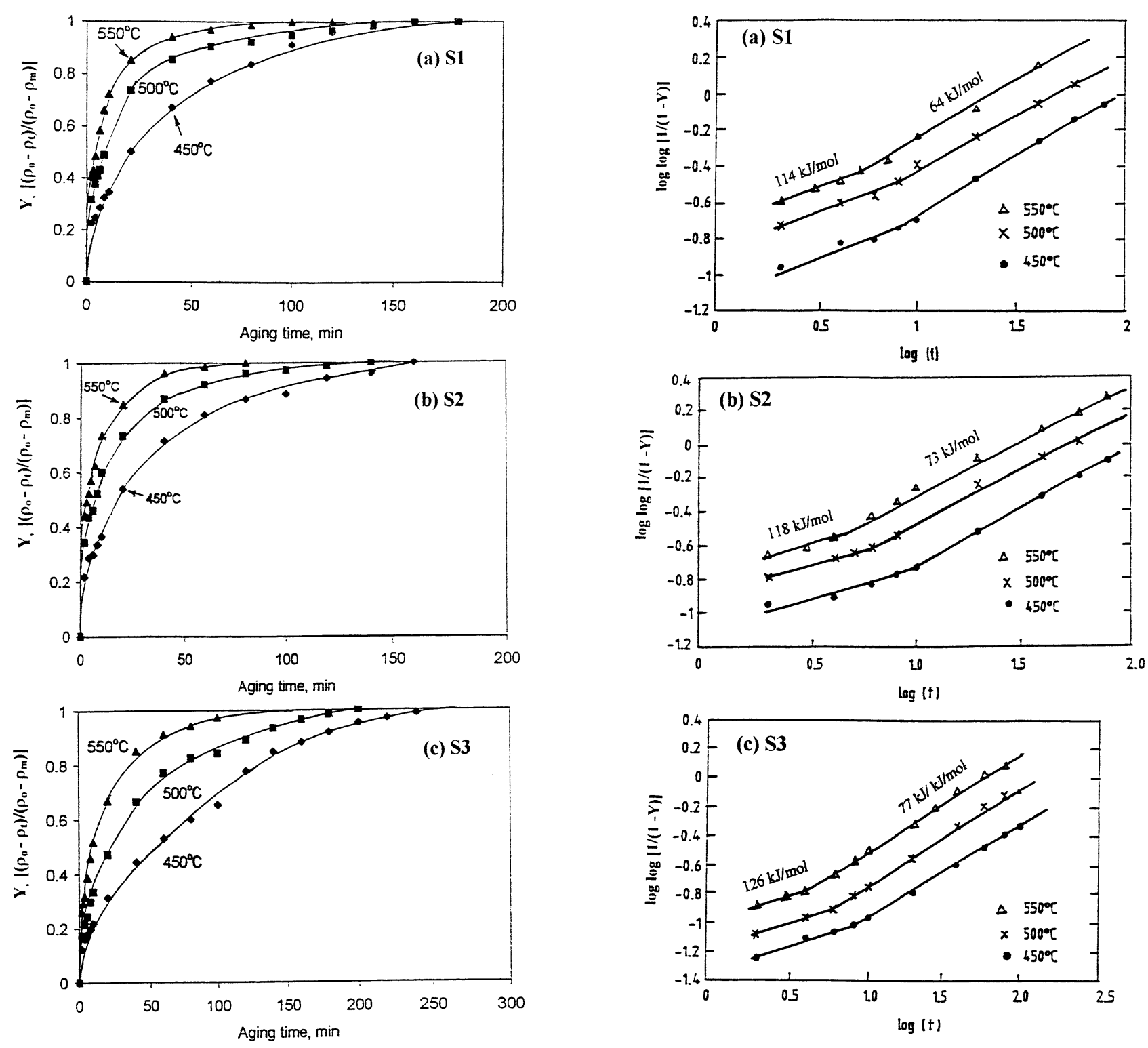

Fig. 9. Fraction of transformation, $Y$, as a function of time during aging of HSLA steels.

Fig. 10. A plot of $\log \log [1 /(1-Y)]$ and $\log t$, where $Y$ denotes fraction transformed and $t$ is time.

Table 2. A comparison of activation energy of copper precipitation during aging observed in the present analysis with that of reported in literature.

\begin{tabular}{|c|c|c|}
\hline Steel & $\begin{array}{c}\text { Activation energy, } \\
\mathrm{kJ} / \mathrm{mol}\end{array}$ & Reference \\
\hline HSLA-80/ HSLA-100 & $114-126$ & Present work \\
\hline HSLA-100 & 140 & Dong \& Young $^{21)}$ \\
\hline $2 \% \mathrm{Cu}$ & 167 & LeMay \& Krishnadev $^{22)}$ \\
\hline Ni-Cu-Nb & 162 & Hydrean $^{23)}$ \\
\hline
\end{tabular}

with the diffusion of $\mathrm{Cu}$ in ferrite when tempering is simultaneously occurring and the value is much lower than that for the diffusion of copper in ferrite $(284 \mathrm{~kJ} / \mathrm{mol}){ }^{20)}$ Dong and Yong ${ }^{21)}$ have also reported low activation energy (140 $\mathrm{kJ} / \mathrm{mol}$ ) during the aging of the $\mathrm{Cu}$ bearing steel. Le May and Krishnadev ${ }^{22)}$ studied the kinetics of aging in a steel containing $2 \mathrm{wt} \% \mathrm{Cu}$ and reported an activation energy of $167 \mathrm{~kJ} / \mathrm{mol}$ in the temperature range of $425-500^{\circ} \mathrm{C}$, which also agrees closely with the values of $162 \mathrm{~kJ} / \mathrm{mol}$ reported by Hydrean et al. ${ }^{23)}$ for $\mathrm{Ni}-\mathrm{Cu}-\mathrm{Nb}$ steel. The activation energy of copper precipitation during aging obtained in the present analysis has been compared with the data reported in the literature ${ }^{25-27)}$ and shown in Table 2. Krishnadev ${ }^{25}$ ) suggested that the lower activation energy might be due to the enhanced diffusion rate in matrix due to the high dislocation density and in that case nucleation rate might determine the precipitation kinetics. The high density of dislocations in as-quenched lath martensite matrix of the present HSLA steels ${ }^{25)}$ may also account for the low value of activation energy $(114-126 \mathrm{~kJ} / \mathrm{mol})$ necessary for the short circuit diffusion.

The unusually low value of empirical activation energy 
Table 3. Estimation of the amount of copper precipitation during heating and isothermal aging at various temperatures from resistivity data.

\begin{tabular}{|c|c|c|c|c|c|}
\hline $\begin{array}{c}\text { T, } \\
{ }^{\circ} \mathrm{C}\end{array}$ & \multicolumn{2}{|c|}{$\begin{array}{c}\Delta \rho, \mathrm{n} \Omega \mathrm{m} \\
\text { HSLA }\end{array}$ LCS } & $\begin{array}{c}\Delta \rho \text { due to Cu } \\
\text { precipitation, } \\
\mathrm{n} \Omega \mathrm{m}\end{array}$ & $\begin{array}{c}\text { Cu ppn. during } \\
\text { aging, wt.\% }\end{array}$ & $\begin{array}{c}\text { Cu ppn. during } \\
\text { heating, wt.\% }\end{array}$ \\
\hline \multicolumn{6}{|c|}{ S1 steel } \\
\hline 500 & 43.6 & 11.2 & 32.4 & 8.1 & 11.4 \\
\hline 550 & 22.5 & 10.8 & 11.7 & 2.9 & 16.2 \\
\hline \multicolumn{7}{|c|}{ S2 steel } \\
\hline 500 & 42.2 & 11.2 & 31.0 & 7.8 & 13.8 \\
\hline 550 & 16.8 & 10.8 & 6.0 & 1.5 & 6.2 \\
\hline \multicolumn{7}{|c|}{ S3 steel } \\
\hline 500 & 34.4 & 11.2 & 23.2 & 5.8 & 8.1 \\
\hline 550 & 25.0 & 10.8 & 14.2 & 3.5 & \\
\hline
\end{tabular}

in the second stage of the precipitation is apparent from the plots in Fig. 10. This process may be related with the tempering in the alloy steel assisted by lattice defects. It may be pointed out that the volume diffusion of carbon in ferrite $(80 \mathrm{~kJ} / \mathrm{mol})^{26)}$ is marginally higher than the activation energy observed for the second stage $(64-77 \mathrm{~kJ} / \mathrm{mol})$.

\subsubsection{Estimation of Copper Precipitation during Aging}

To estimate the decrease in resistivity due to copper precipitation alone in the HSLA steels, the resistivity drop in the low carbon steel (LCS) due to tempering was subtracted from that of the HSLA steels at each temperature. The remnant decrease in the resistivity was assumed to be due to the precipitation of copper alone. It is expected that a part of copper will precipitate out during heating and the remaining during the isothermal aging period. Using the effect of copper on the resistivity and equilibrium solubility of copper in iron, ${ }^{27,28)}$ the percentage of copper precipitated during heating as well as during isothermal aging was calculated for all three steels and shown in Table 3. A typical calculation is presented in Appendix 2. As expected, the amount of copper precipitation during heating increased with the increase in the temperature, whereas the amount of copper precipitation decreased during isothermal aging with rise in $T_{\mathrm{A}}$. For example, in case of $\mathrm{S} 1$ steel, the amount of copper precipitation during heating to 450, 500 and $550^{\circ} \mathrm{C}$ was estimated as $0.98,1.1$ and $1.6 \mathrm{wt} \%$, respectively, while during aging at these temperatures, the amount of copper precipitation was $0.99,0.81$ and $0.29 \mathrm{wt} \%$. It is interesting to note that the estimated amount of copper precipitation during heating matches well with that determined from the resistivity measurements during continuous heating on these steels reported elsewhere. ${ }^{25)}$ It is also observed that amount of copper precipitation during heating as well as during aging varies with the composition of the steel. The amount of $\mathrm{Cu}$ precipitation in $\mathrm{S} 3$ steel was lower in both the stages i.e. during heating as well as during isothermal aging than that of the S1 or S2 steel (Table 3). It is possibly because of the lower amount of $\mathrm{Cu}$ in $\mathrm{S} 3$ steel.

\subsubsection{Resistivity Behaviour at Higher Temperature of Aging}

At higher aging temperatures $\left(650\right.$ and $\left.700^{\circ} \mathrm{C}\right)$, the resistivity rises with aging time after an initial fall (Fig. 3), whereas the hardness decreases continuously (Fig. 6). The decrease of hardness is believed to be associated with the coarsening as well as some dissolution of copper precipitates. The dissolution of copper appears to be one reason for the rise in resistivity. Further, the magnetic transition concurrently occurring with the transformation also contributes to this increase. However there could be second order influences on the resistivity values due to the presence of point defects i.e. vacancies.

\subsection{Mechanical Properties}

The hardness $v s$. aging temperature $\left(T_{\mathrm{A}}\right)$ plot in Fig. 4 shows a rise and then a fall in the hardness value with the increase in the aging temperature for all three steels. The increase in the hardness is believed to be associated with the formation of fine copper precipitates. Fine copper precipitates in $\mathrm{Cu}$ bearing steels have been reported to increase the hardness and strength by several investigators. ${ }^{2,3)}$ During aging of the quenched steel, two phenomena are expected to occur together i.e. tempering process and copper precipitation. The tempering is associated with the annihilation of dislocations and precipitation of carbides resulting in a fall in hardness. The copper is expected to precipitate out during aging forming fine copper precipitates causing a rise in hardness value. It is reported that the hardness reaches its maximum level when the precipitate is of critical size. ${ }^{729)}$ The aging temperature corresponding to the peak hardness for $\mathrm{S} 1$ steel is lower by around $50^{\circ} \mathrm{C}$ than that for S2 and S3 steels, whereas the magnitude of the peak hardness of S1 steel is higher than that of S2 and S3 steels. The higher value of peak hardness for S1 steel may be attributed to the higher amount of $\mathrm{Cu}$ in $\mathrm{S} 1$ steel.

The fall in the hardness value for $T_{\mathrm{A}}>500^{\circ} \mathrm{C}$ for $\mathrm{S} 1$ and above $550^{\circ} \mathrm{C}$ for $\mathrm{S} 2$ and $\mathrm{S} 3$ steels (Fig. 4) is believed to be associated with the overaging phenomenon as in the classical age hardening systems. In copper bearing steels, copper rich clusters (one or two atoms thick) form. They are coherent with the matrix and cause elastic strains. The cluster formation occurs by a short-range diffusion of copper in a quenched material. As the temperature increases, the clusters disappear and the intermediate phases form before they re-dissolve in the matrix. ${ }^{9)}$ The hardness is maximum when the precipitate is semi-coherent and of a critical size. The critical size of copper precipitates in $\mathrm{Fe}-\mathrm{Cu}$ steel is reported to be $2.4 \mathrm{~nm}^{7,29)}$ when the hardness attains its maximum. It 
seems that the size of the precipitates plays a significant role here. The fall in the hardness above $500^{\circ} \mathrm{C} / 550^{\circ} \mathrm{C}$ is associated with the formation of coarser $\mathrm{Cu}$ precipitates.

The hardness $v s$. aging time plot for $T_{\mathrm{A}}=450-550^{\circ} \mathrm{C}$ initially shows a marginal fall, then it rises, reaches a peak and falls at longer time. The initial decrease in hardness may be attributed to the tempering of the martensite at low aging temperature $\left(\leq 500^{\circ} \mathrm{C}\right)$. The increase in the hardness in the next stage may be due to the age hardening by the copper precipitation. The increase in hardness and strength due to copper precipitation has been well documented by previous authors. ${ }^{2,3,9)}$ For example, Ghasemi et al. ${ }^{2)}$ have reported the hardness as a function of aging time in different initial microstructure of $1.1 \mathrm{wt} \%$ copper steel. The initial decrease in hardness was interpreted by the tempering process. However, TEM work conducted on the S1 steel reported elsewhere ${ }^{29)}$ revealed the presence of fine copper precipitates in $\mathrm{S} 1$ steel sample aged at $450^{\circ} \mathrm{C}$ leading to the peak hardness value; but the samples aged at $650^{\circ} \mathrm{C}$ revealed coarser precipitates. In over aged condition at $650^{\circ} \mathrm{C}$, Ghasemi et $a ._{.}^{2)}$ have also observed the coarse precipitates, which were easily detectable by TEM. The coarsening of the precipitates seems to be responsible for the fall in hardness at higher $T_{\mathrm{A}}$ i.e., $650-700^{\circ} \mathrm{C}$ (Fig. 4). It is also observed that the time to reach the peak hardness value decreases with the increase in $T_{\mathrm{A}}$. It is interesting to note that the time to achieve the minimum resistivity follows the same trend (Fig. 2). In fact, the time to reach the peak hardness value at given $T_{\mathrm{A}}$ is of the same order of magnitude as the time corresponding to minimum resistivity indicating a similar underlying process. In the over-aging period, the hardness decreases (Fig. 5) due to coarsening of copper precipitates, whereas during that period the resistivity is almost constant (Fig. 2) as there is no further change in the solute content.

An abrupt fall in the impact strength after aging of the quenched HSLA steels at $450^{\circ} \mathrm{C}$ has been observed here (Fig. 7). It is plausible that the formation of coherent $\mathrm{Cu}$ precipitates makes the steel brittle ${ }^{25}$ ) that causes the decrease in the toughness values. The harmful effect of coherent precipitates on the toughness has been dealt with by Leysen et $a l^{30)}$ for the microalloyed steel and by SkoufariThemistou et al. ${ }^{31)}$ in $\mathrm{C}-\mathrm{Mn}-\mathrm{Al}-\mathrm{Cu}$ steel. The toughness values increase beyond the aging temperature of $500^{\circ} \mathrm{C}$, reach a peak at $650^{\circ} \mathrm{C}$ and again decrease slightly at $700^{\circ} \mathrm{C}$. The change in the toughness behaviour is believed to be due to the transformation from semi-coherent to incoherent precipitates. The coexistence of coherent and incoherent precipitates in $5 \% \mathrm{Ni}-2 \% \mathrm{Al}$ steel has been reported to prevent the local strain concentration and early cleavage fracture. This was believed to be due to the fact that the coherent precipitates strengthened the matrix, while the incoherent precipitates increased the strength as well as toughness of the material. Skoufari-Themistou et al. ${ }^{31)}$ also reported that the incoherent precipitates increased the strength without affecting the impact property. Indeed, a small improvement in the toughness was also observed. In the present case, a large increase in the impact properties for $T_{\mathrm{A}}=$ $650^{\circ} \mathrm{C}$ (from approximately $160 \mathrm{~J}$ for a quenched sample to $200 \mathrm{~J}$ for the aged samples of all three steels) was observed. Fractography studies by SEM also indicate a change in the fracture behaviour from cleavage/mix mode to dimple mode of fracture with the rise in aging temperature from 450 to $650^{\circ} \mathrm{C}$ (Fig. 8), which is in good agreement with that of the impact properties.

\section{Conclusions}

Isothermal aging of HSLA steel in the temperature range of $450-550^{\circ} \mathrm{C}$ seems to occur in two stages. The first stage, presumably associated with copper precipitation, has activation energy in the range of $114-126 \mathrm{~kJ} / \mathrm{mol}$, which is much lower than that for diffusion of copper in ferrite (284 $\mathrm{kJ} / \mathrm{mol}$ ) apparently indicating the dominant influence of high density of dislocation in the quench matensite matrix on the diffusive mass transfer during aging. In the second stage, the lower activation energy $(64-77 \mathrm{~kJ} / \mathrm{mol})$ may be ascribed to the diffusion of carbon in ferrite during tempering of the HSLA steel in presence of the lattice defects. The peak hardness during isothermal aging was achieved in the aging temperature range of $500-550^{\circ} \mathrm{C}$, whereas the toughness of the steel was found to be lowest for $T_{\mathrm{A}}=450^{\circ} \mathrm{C}$. The hardness decreases with the increase in $T_{\mathrm{A}}$, while a sharp rise in the toughness value was observed with the increase in $T_{\mathrm{A}}$ from 450 to $650^{\circ} \mathrm{C}$. Fracture surface examination by SEM reveals a change from cleavage/mix mode to dimple mode of fracture with the increase in aging temperature, which is in conformity with the results of impact property measurements.

\section{Acknowledgements}

Financial support of the Naval Research Laboratory (NRL), Washington (DC), USA under grant no. N0001495-1-0015 to carry out this work is gratefully acknowledged. They would also like to thank Dr. S. Pramanik, a retired Scientist of NML, for his help in resistivity measurements. Two of the authors [ANB and ONM] also record their appreciation to Tata Steel for permission to carry out this work and publish this paper.

\section{REFERENCES}

1) E. J Czyryca: Conf. Proc. on Advances in Low Carbon High Strength Ferrous Alloys, eds. by O. N. Mohanty, B. B. Rath and C. S. Sivaramakrishnan, Trans. Tech. Pub., Switzerland, 84-85 (1993), 491.

2) S. S. B. Ghasemi, D. Yu and D. P. Dunne: ISIJ Int., 36 (1996), 61.

3) M. Mujahid, A. K. Lis, C. I. Gracia and A. J. DeArdo: Conf. Proc. on Advances in Low Carbon High Strength Ferrous Alloys, ed. by O. N. Mohanty, B. B. Rath and C. S. Sivaramakrishnan, Trans. Tech. Pub., Switzerland, 84-85 (1993), 209.

4) E. Hornbogen and R. C. Glenn: Trans. Metall. Soc. AIME, 218 (1960), 1064.

5) E. Hornbogen: Trans. Am. Soc. Met., 57 (1964), 120.

6) M. T. Miglin, J. P. Hirth, A. R. Rosenfield and W. A. T. Clark: Metall. Trans., 17A (1986), 791.

7) S. R. Goodman, S. S. Brenner and J. R. Low: Metall. Mater. Trans., 4 (1973), 2363.

8) K. Osamura, H. Okuda, S. Ochiai., M. Takashima, K. Asano, M. Furusaka, K. Kishida and F. Kurosawa: ISIJ Int., 34 (1994), 359.

9) K. C. Russel and L. M. Brown: Acta Metall., 20 (1970), 969.

10) D. P. Dunne, S. S. B. Ghasemi and D. Yu: ISIJ Int., 36 (1996), 324.

11) S. W. Thompson and G. Krauss: Metall. Mater. Trans., 27A (1996), 1573.

12) C. S. Pande, M. A. Imam, C. L. Vold, E. Dantsker and B. B. Rath: Conf. Proc. on Advances in Low Carbon High Strength Ferrous Alloys, ed. by O. N. Mohanty, B. B. Rath and C. S. 
Sivaramakrishnan, Trans. Tech. Pub., Switzerland, 84-85 (1993), 145.

13) D. T. Peter and C. R. Cupp: Trans. AIME, 236 (1966), 1420

14) R. Simoneau, G. Begin and A. H. Marquis: Met. Sci., 12 (1978), 381

15) M. Ahmad, M. Farooque, F. H. Hasmi, S. W. Hussain and A. Q. Khan: Proc. Symp. Maraging Steels, Recent Dev. \& Application, ed. by R. K. Wilson, TMS, Warrendale, PA, (1988), 269.

16) O. N. Mohanty: Mater. Sci. Eng., B22 (1995), 267.

17) M. Avrami: J. Chem. Phys., 8 (1940), 212

18) M. Avrami: J. Chem. Phys., 9 (1940), 177

19) W. A. Johnson and R. F. Mehl: Trans. AIME, 135 (1939), 416.

20) E. A. Brandes and G. B. Brook: Smithells Metal Ref. Book, Butterwarth-Heinemann Ltd., Oxford, 7th ed., (1992), Ch. 13.

21) W. Dong and R. Yang: J. Univ. Sci. Technol., 18 (1996), 18

22) I. Le May and M. R. Krishnadev: Proc. ICSTIS, 6, Suppl. Trans. Iron Steel Inst. Jpn., 11 (1971), 1005.

23) P. P. Hydrean: Metall. Mater. Trans., 2 A (1971), 2541.

24) A. N. Bhagat: Ph. D. Thesis, IIT Kharagpur, India, (2002).

25) M. R. Krishnadev: INCRA Report No. 244, New York, (Oct. 1974).

26) A. K. Jena and M. C. Chaturvedi: The Phase Transformations in Materials, Prentice Hall, New Jersey, (1992), 103.

27) A. L. Norbury: J. Iron Steel Inst., 101 (1920), 627.

28) H. A. Wriedt and L. S. Darken: Trans. Metall. Soc. AIME, 218 (1960), 30.

29) K. Osamura., H. Okuda, M. Takashima., K. Asano. and M. Furusaka: Trans. Jpn. Inst. Met., 34 (1993), 305.

30) F. Leysen., J. Neutjens., K. Mols., S. Vandeputte and Y. Houbaert: Mater. Sci. Forum (Switzerland), 284-286 (1998), 263

31) L. Skoufari-Themistou, B. Mintz and D. N. Crowther: Mater. Sci. Technol., 15 (1999), 1069.

\section{Appendix 1. Kinetics of Tempering in Plain Carbon Steel}

From Fig. 1, it is observed that the tempering process follows approximately a first order kinetics, and the fractional change in the resistivity $Y_{\text {tem }}$ in this region can be represented as a function of time $t$ (in minutes) as follows:

$$
\begin{aligned}
& \log \left(1-Y_{\text {tem }}\right)=-0.14 t+0.04 \text { at } 450^{\circ} \mathrm{C} \ldots \ldots .(\mathrm{A}-1) \\
& \log \left(1-Y_{\text {tem }}\right)=-0.49 t+0.05 \text { at } 650^{\circ} \mathrm{C} \ldots \ldots .(\mathrm{A}-2)
\end{aligned}
$$

The slope and intercept for such relations at intermediate temperature can be evaluated by interpolation, if a linear variation of these two parameters is assumed within the range of $450-650^{\circ} \mathrm{C}$. As the approximation is made for a relatively narrow range of temperature, it is not expected to cause any significant error. The functions derived from such interpolation for temperature of 500 and $550^{\circ} \mathrm{C}$ may be presented as follows:

$$
\begin{array}{ll}
\log \left(1-Y_{\text {tem }}\right)=-0.23 t+0.04 & \text { at } 500^{\circ} \mathrm{C} \ldots . .(\mathrm{A}-3) \\
\log \left(1-Y_{\text {tem }}\right)=-0.315 t+0.04 & \text { at } 550^{\circ} \mathrm{C} \ldots . .(\mathrm{A}-4)
\end{array}
$$

\section{Appendix 2. Estimation of the Amount of Cu Precipi- tation from Resistivity Data}

Let the decrease in resistivity of HSLA steel during aging at temperature $T=A \mathrm{n} \Omega \mathrm{m}$, and the decrease in resistivity during aging at temperature $T$ in plain $\mathrm{C}$ steel= $B \mathrm{n} \Omega \mathrm{m}$.

Therefore, the decrease in resistivity due to $\mathrm{Cu}$ precipitation alone during aging $=(A-B) \mathrm{n} \Omega \mathrm{m}$.

Since $1 \mathrm{wt} \% \mathrm{Cu}$ in iron causes an increases the resistivity by $40 \mathrm{n} \Omega \mathrm{m},{ }^{27)}$ the $\mathrm{wt} \%$ of $\mathrm{Cu}$ precipitated during aging, $\mathrm{Cu}_{\text {aging }}=(A-B) / 40$.

If the solid solubility of $\mathrm{Cu}$ in iron at the temperature $T=S$, and the effect of alloying on the equilibrium solubility of $\mathrm{Cu}$ at $T$ is negligible, we may write:

The total amount of $\mathrm{Cu}$ in the HSLA steel $=\mathrm{Cu}$ precipitated during heating $+\mathrm{Cu}$ precipitated during aging $+\mathrm{Cu}$ present in solid solution $=\mathrm{Cu}$ heating $+\mathrm{Cu}$ aging $+S$.

Since total amount of copper in the steel is known from its chemical analysis, the amount of $\mathrm{Cu}$ precipitated during heating $\left(\mathrm{Cu}_{\text {heating }}\right)$ can be estimated from the resistivity measurements. 